\title{
Beauveria bassiana for the simultaneous control of Aedes albopictus and Culex pipiens mosquito adults shows high conidia persistence and productivity
}

\author{
Jin Yong Lee ${ }^{1 \dagger}$, Ra Mi Woo ${ }^{2 \dagger}$, Cheol Jun Choi ${ }^{1}$, Tae Young Shin ${ }^{3}$, Won Seok Gwak and Soo Dong Woo ${ }^{1 *}$ (])
}

\begin{abstract}
This study was conducted to determine the optimal entomopathogenic fungus for the simultaneous control of the adults of two mosquito species, Aedes albopictus and Culex pipiens. The pathogenicity and virulence against the two species of mosquitoes were evaluated by using 30 isolates of Beauveria bassiana, an entomopathogenic fungus isolated from Korea that has high thermotolerance and UV-B tolerance. Regarding pathogenicity, 23 isolates were pathogenic to Ae. albopictus and 12 isolates were pathogenic to $C$. pipiens; Ae. albopictus adults were more susceptible to $B$. bassiana than $C$. pipiens adults. Among the isolates, 6 isolates that were simultaneously pathogenic to the two species of mosquitoes were used to evaluate virulence and conidia productivity. B. bassiana CN6T1W2 and JN5R1W1 had higher virulence than the other isolates, and they were more virulent in Ae. albopictus than inCX. pipiens. The conidia productivity of $B$. bassiana JN5R1W1 on millet grain medium was higher than that of B. bassiana CN6T1W2. Based on these results, B. bassiana JN5R1W1 was selected as the most efficient isolate for the simultaneous control of the two mosquito species. B. bassiana JN5R1W1 can be used effectively in the development of fungal insecticides to simultaneously control Ae. albopictus and CX. pipiens adults with similar distribution areas.
\end{abstract}

Keywords: Beauveria bassiana, Aedes albopictus, Culex pipiens, Simultaneous control, Mosquito adults

\section{Introduction}

Mosquitoes are the most important vectors of severe human viral diseases, such as malaria, dengue, chikungunya, Zika, West Nile, and urban yellow fever, in tropical and subtropical regions (Mayer et al. 2017; Weaver et al. 2018). Mosquitoes are considered to be the most important vector species in the world, not only because of their susceptibility to these diseases but also because they target more than one host during their lifecycle (Fernandes et al. 2018; Harrington et al. 2001). Among the

\footnotetext{
*Correspondence: sdwoo@cbnu.ac.kr

${ }^{\dagger}$ Jin Yong Lee and Ra Mi Woo contributed equally to this work

1 Department of Agricultural Biology, College of Agriculture, Life \& Environment Science, Chungbuk National University, Cheongju 28644, Republic of Korea

Full list of author information is available at the end of the article
}

mosquitoes, the Asian tiger mosquito, Aedes albopictus (Skuse) (Diptera: Culicidae), transmits many viral diseases, such as yellow fever, dengue and chikungunya. It is also believed to have the potential for Zika transmission among humans due to the host capacity of the Zika virus (Hochedez et al. 2006; Wong et al. 2013). In addition, the house (or northern house) mosquito, Culex pipiens (L.) (Diptera: Culicidae), is a temperate Eurasian nocturnal mosquito that has established populations throughout temperate North America (Farajollahi et al. 2011). Culex pipiens may be strong nuisance and mediate a number of infectious diseases, such as Japanese encephalitis, West Nile, and Rift Valley fever virus (Farajollahi et al. 2011). Moreover, since these mosquito species are present in areas that contain more than half of the world's population, continuous mosquito control efforts are needed 
to prevent the prevalence of these diseases (Khaiboullina et al. 2018; Kraemer et al. 2015; Lounibos 2002). In addition, due to recent global climate anomalies, the distribution of these mosquito species and related arboviral diseases are spreading (Shuman 2011). Therefore, these mosquitoes are two major mosquito vectors whose importance is increasing globally. However, since there are no vaccines against these viruses, except for Japanese encephalitis, controlling the mosquitoes that spread them is a method to prevent a pandemic due to these diseases.

There are two methods for controlling mosquitoes: chemical and biological control. Chemical control has been widely used as a major strategy to control mosquito density. However, the side effects of synthetic chemical insecticides in the environment have become widely popular concerns (Hemingway and Ranson 2000; Liu 2015; Moyes et al. 2017). Over the past several decades, the use of synthetic chemical insecticides by agricultural and public health programmes have caused many problems, including insecticide resistance, environmental pollution, and toxicity to humans and non-target organisms (Ariee et al. 2001; Damalas and Eleftherohorinos 2011; Mužinić and Želježić 2018). Therefore, integrated control methods have been attempted to overcome these limitations, but new strategies have been demanded because the integrated methods have not been effective thus far (Patterson 2016). The most attractive method is biological control.

One of the most successful biological control methods is mosquito larval control using Bacillus thuringiensis israelensis (Bti) and Lysinibacillus sphaericus (Berry 2011). Larval control is effective; however, adult control is largely dependent on synthetic chemical insecticides and the control effect has not been achieved. Therefore, it is necessary to develop a new biological control method for adult mosquito control; the representative method is to use entomopathogenic fungi. Entomopathogenic fungi are already widely used in agricultural pest control and are considered harmless and safe to humans and other animals (Lacey et al. 2001, 2015). In particular, they have a great advantage of infecting insects, including mosquitoes, through contact with spores compared to other biological control agents that need to be ingested, such as bacteria, viruses and protozoa. Fungal insecticides using various entomopathogenic fungi have been widely developed for agricultural pests, but despite much effort in their development for mosquito control, authentic products have only recently been developed and require more research efforts (Buckner et al. 2017; Snetselaar et al. 2014).

Among the entomopathogenic fungi used in biopesticide development, Beauveria bassiana and Metarhizium anisopliae are the most widely used (Lacey et al.
2015). These fungi have a relatively wide host range and are regarded as environmentally friendly fungi; various biopesticides have been developed with these agents to control agricultural pests and vectors such as ticks, termites and house flies (Lacey et al. 2001, 2015). In particular, $M$. anisopliae has been studied in a variety of mosquito species, but B. bassiana has been rarely studied in mosquitoes (Huang et al. 2017; Scholte et al. 2004). Virulence and persistence together with the productivity of conidia is required to determine the potential of a fungus for further development as a successful biopesticide (Fernandes et al. 2008, 2015; Lee et al. 2015; Lopez-Perez et al. 2015; Muñiz-Paredes et al. 2017; Samish et al. 2014). In the past, the selection of fungi for the development of biopesticides was mainly focused on virulence, and they was difficult to put into practical use due to problems with the persistence and productivity of fungal conidia. Therefore, recently, a simultaneous evaluation method for virulence, spore persistence and productivity using a large number of fungi has emerged. To date, the selection of fungi against mosquitoes has also been conducted with a focus on virulence, making it difficult to develop successful products.

To develop a successful fungal insecticide for the simultaneous control of Ae. albopictus and Cx. pipiens mosquito adults, our study was conducted to select fungi with high virulence and high conidia persistence and productivity. For this purpose, the virulence against mosquito adults and the conidia productivity of $B$. bassiana isolates with high conidia persistence among 342 fungal isolates from Korea (Shin et al. 2013) was evaluated. The most effective fungal isolates were finally selected by evaluating the conidia productivity of the selected fungal isolates.

\section{Materials and methods Mosquitoes}

Aedes albopictus and Cx. pipiens mosquitoes were obtained from a colony at the laboratory of Insect Ecology and Toxicology, Chungbuk National University, Korea, and have been cultured under laboratory conditions. A single generation of mosquito adults was reared by placing eggs in plastic trays containing water to which $1 \mathrm{~g}$ of fish food was added. Larval trays were covered with a netting material. Larvae were fed fish food daily. Pupae were manually removed and placed in $30 \mathrm{~cm}$ cubic net cages. Adult males were provided with $10 \%$ sucrose solution, while females were fed twice per week on the blood of white mice. All of the mosquitoes were maintained at $28 \pm 2{ }^{\circ} \mathrm{C}$ and $75 \pm 5 \% \mathrm{RH}$ with a $12 \mathrm{~h}$ photoperiod. 


\section{Fungi}

One hundred nine isolates of B. bassiana from 342 entomopathogenic fungal strains isolated in Korea (Shin et al. 2013) were used. Fungal isolates were cultured on potato dextrose agar (PDA) plates for 14 days at $25{ }^{\circ} \mathrm{C}$. Then, 14-day-old fungal conidia were collected by scraping the fungi from the PDA plates and resuspending the material in a $0.01 \%$ Tween- 80 (Difco, USA) solution. The conidial suspension was vigorously stirred and filtered through cotton to remove the mycelial debris. The conidial concentration was determined using a haemocytometer.

\section{Thermotolerance and UV-B tolerance for conidial germination}

To evaluate the thermotolerance for conidial germination, $100 \mu \mathrm{L}$ of conidial suspensions $\left(5 \times 10^{6}\right.$ conidia/ $\mathrm{mL}$ ) were transferred to sterile PCR tubes and immediately placed in a thermal cycler adjusted to $45{ }^{\circ} \mathrm{C}$. Aliquots $(20 \mu \mathrm{L})$ were removed after $4 \mathrm{~h}$ and plated (without spreading) on Sabouraud dextrose agar (SDA; Difco TM, USA) with $0.5 \mu \mathrm{g} / \mathrm{mL}$ of benomyl (95\% active ingredient) (SDA-B) (Fernandes et al. 2008). Plates were incubated at $25{ }^{\circ} \mathrm{C}$ for $24 \mathrm{~h}$ before microscopic observation of germination. For the evaluation of conidial germination following UV-B irradiation, $20 \mu \mathrm{L}$ of a conidial suspension $\left(5 \times 10^{6}\right.$ conidia/mL) from each isolate was plated (without spreading) on SDA-B. Conidia were immediately exposed to irradiances of $0.2 \mathrm{~J} / \mathrm{cm}^{2}$ in a UV irradiation chamber (Bio-Link-BLX-E254, Vilber Lourmat, France) at $25^{\circ} \mathrm{C}$ (Fernandes et al. 2015). After exposure, the plates were incubated at $25{ }^{\circ} \mathrm{C}$. Control conidial suspensions were not exposed to UV-B but were inoculated on SDA-B at $25{ }^{\circ} \mathrm{C}$. The relative percent germination was calculated by comparing germination to untreated isolates. At least 100 conidia were examined for each treatment in every experiment.

\section{Bioassay}

Fourteen-day-old fungal conidia were used for the bioassay. A conidial suspension with more than $90 \%$ viability was used for the bioassay. The viability of conidia was determined on SDA-B. The bioassays were designed in two steps. First, the fungal isolates were tested for pathogenicity against mosquito adults. Bioassays were conducted in a plastic cylinder (height 18, diameter $9 \mathrm{~cm}$ ) capped with netting material. To evaluate the pathogenicity of the fungus, 10 mosquito adults aged 1-2 days were placed in the cylinder, and $1 \mathrm{~mL}$ of a conidial suspension $\left(1 \times 10^{8}\right.$ conidia/mL) was sprayed into each cylinder using an SD tower sprayer (Shin et al. 2011). Cotton wool freshly soaked with a $10 \%$ sucrose solution was placed on the netting. The control group was treated with the same method but without conidia. To determine whether the dead mosquitoes had been infected by the fungus, after 10 days of treatment, all the mosquito cadavers were removed from the cylinder and maintained at over $90 \% \mathrm{RH}$ in an incubator at $25 \pm 1{ }^{\circ} \mathrm{C}$ for 7 days. Cadavers with visible fungal growth on their body surface were considered to have died as a result of fungal infection. Additional bioassays were performed to determine the virulence of the fungal isolates. Twenty mosquitoes were used in the bioassay with the same methods described above. Mosquitoes were checked daily for mortality, and the bioassay was repeated three times.

\section{Conidia productivity}

Conidia were produced in Petri dishes on Italian millet grains (Setaria italica Beauvois). Millet grains for the production of conidia were prepared according to a previous report (Kim et al. 2011). Briefly, millet grains were placed in a polyvinyl bag and soaked in a half volume of water containing $0.15 \%$ citric acid. The bag was held at $95{ }^{\circ} \mathrm{C}$ for $15 \mathrm{~min}$ and then autoclaved at $121{ }^{\circ} \mathrm{C}$ for $30 \mathrm{~min}$. After cooling to ambient temperature, the millet grains ( $5 \mathrm{~g}$ ) were divided into the Petri dishes and inoculated with a suspension of $1 \times 10^{7}$ conidia $(1 \mathrm{~mL})$. The conidia on the millet grains were collected daily and counted using a haemocytometer.

\section{Statistical analysis}

The mortality data were analysed by SPSS statistical software ver. 25.0 (SPSS, Inc., Chicago, IL, USA). The lethal time for the treatments was analysed with probit analysis. Data were expressed as the mean \pm standard error $(\mathrm{SE})$, and statistical significance was set at the conventional $\alpha<0.05$ level.

\section{Results}

Evaluation of thermotolerance and UV-B tolerance

Most of the $109 \mathrm{~B}$. bassiana isolates used in this study showed low thermotolerance but high UV-B tolerance (Additional file 1: Table S1). The isolates with more than $50 \%$ thermotolerance accounted for $10.1 \%$ (11 isolates), and those with $30 \%$ or more accounted for only $43.1 \%$. On the other hand, most of the fungal isolates showed more than $50 \%$ UV-B tolerance, and $67.9 \%$ of the isolates showed more than $70 \%$ tolerance. As most of the isolates had high UV-B tolerance, 30 isolates were selected based on thermotolerance and used for the evaluation of pathogenicity against the mosquito adults (Table 1).

\section{Pathogenicity to mosquito adults}

The pathogenicity of the fungi to Ae. albopictus and $C x$. pipiens mosquito adults was examined using 30 isolates 
Table 1 Thermotolerance and UV-B tolerance of $B$. bassiana isolates

\begin{tabular}{|c|c|c|}
\hline \multirow[t]{2}{*}{ B. bassiana isolates } & \multicolumn{2}{|c|}{ Conidial germination (\%) } \\
\hline & $\begin{array}{l}\text { Exposure to } 45^{\circ} \mathrm{C} \\
\text { for } 2 \mathrm{~h}\end{array}$ & $\begin{array}{l}\text { Exposure } \\
\text { to UV-B } \\
\text { on } 0.2 \mathrm{~J}\end{array}$ \\
\hline KG22R3W1 & 79.99 & 94.56 \\
\hline JB6G3W1 & 63.21 & 82.64 \\
\hline KW10S1W1 & 62.20 & 100.00 \\
\hline JN19M2W1 & 61.05 & 88.81 \\
\hline JN16R1W1 & 60.10 & 80.17 \\
\hline CN3R2W1 & 60.04 & 75.80 \\
\hline DK4T4W1 & 58.89 & 86.05 \\
\hline CB12M1W1 & 57.46 & 91.33 \\
\hline KN3S1W1 & 54.23 & 84.90 \\
\hline JN5R1W1 & 52.25 & 72.03 \\
\hline CB3S3W2 & 50.69 & 67.45 \\
\hline JB7R3W1 & 49.46 & 72.06 \\
\hline JB13S1W1 & 46.81 & 86.17 \\
\hline CN6T1W2 & 46.13 & 79.71 \\
\hline KB6S1W1 & 45.98 & 92.25 \\
\hline JB13G1W1 & 45.58 & 83.24 \\
\hline CN14S2W1 & 45.11 & 80.77 \\
\hline JN19M4W1 & 44.31 & 67.70 \\
\hline CB12G2W1 & 44.10 & 81.69 \\
\hline KN16G1W1 & 43.84 & 72.75 \\
\hline JN15T2W1 & 43.30 & 63.51 \\
\hline KN13S1W1 & 43.21 & 66.09 \\
\hline KG1G2W1 & 42.54 & 62.13 \\
\hline CN5R1W1 & 42.11 & 87.20 \\
\hline CN13R1W1 & 40.99 & 75.19 \\
\hline CN5G1W1 & 39.72 & 100.00 \\
\hline KG19S1W1 & 39.08 & 71.46 \\
\hline CN10G3W2 & 38.68 & 74.37 \\
\hline KG11G1W1 & 37.92 & 66.37 \\
\hline KW10G7W1 & 37.67 & 78.76 \\
\hline
\end{tabular}

of $B$. bassiana that had a high thermotolerance and $\mathrm{UV}$-B tolerance. The conidia of the selected isolates were applied to the two species of mosquitoes, and only the isolates that produced confirmed mycosis of the cadavers were considered pathogenic B. bassiana isolates. As a result, typical fungal symptoms were observed over time in dead mosquitoes after conidia treatment (Additional file 2: Figure S1). Twenty-three isolates were found to be pathogenic against Ae. albopictus and 12 isolates were pathogenic against $C x$. pipiens adults (Table 2). Among the pathogenic isolates, 6 were determined to be simultaneously pathogenic to Ae. albopictus and Cx. pipiens adults.
Table 2 Pathogenicity of $B$. bassiana isolates against Ae. albopictus and $C$. pipiens mosquito adults

\begin{tabular}{|c|c|c|}
\hline \multirow[t]{2}{*}{ B. bassiana isolates } & \multicolumn{2}{|l|}{ Pathogenicity } \\
\hline & Ae. albopictus & Cx.pipiens \\
\hline CB12G2W1 & $x$ & $x$ \\
\hline CB3S3W2 & 0 & $x$ \\
\hline CB12M1W1 & 0 & x \\
\hline CN6T1W2 & 0 & 0 \\
\hline DK4T4W1 & O & $x$ \\
\hline KW10G7W1 & 0 & $x$ \\
\hline KW10S1W1 & ○ & $x$ \\
\hline JB13G1W1 & O & $x$ \\
\hline JB6G3W1 & 0 & $x$ \\
\hline JB7R3W1 & O & $x$ \\
\hline JB13S1W1 & O & $x$ \\
\hline JN19M2W1 & $\triangle$ & 0 \\
\hline JN16R1W1 & O & $x$ \\
\hline JN5R1W1 & O & 0 \\
\hline JN15T2W1 & 0 & 0 \\
\hline JN19M4W1 & 0 & $x$ \\
\hline KG1G2W1 & 0 & $x$ \\
\hline KG1 1G1W1 & 0 & $x$ \\
\hline KN3S1W1 & $\triangle$ & O \\
\hline KN16G1W1 & 0 & 0 \\
\hline KN13S1W1 & O & $x$ \\
\hline KG22R3W1 & $x$ & O \\
\hline KG19S1W1 & O & $x$ \\
\hline KB6S1W1 & O & 0 \\
\hline CN13R1W1 & 0 & $x$ \\
\hline CN3R2W1 & $\triangle$ & O \\
\hline CN10G3W2 & O & O \\
\hline CN5R1W1 & $x$ & 0 \\
\hline CN14S2W1 & $\triangle$ & 0 \\
\hline CN5G1W1 & 0 & $x$ \\
\hline
\end{tabular}

$\mathrm{O}$ : Showed death and mycosis; $\mathrm{X}$ : did not show death; $\triangle$ : showed death but did not mycosis

\section{Virulence in mosquito adults}

The virulence of 6 isolates of B. bassiana that were simultaneously pathogenic to Ae. albopictus and $C x$. pipiens adults was evaluated against each mosquito species. The pathogenicity of the 6 isolates was confirmed in both mosquito species; 4 isolates pathogenic to Ae. albopictus and 5 isolates pathogenic to $C x$. pipiens showed $100 \%$ mortality at 10 days after treatment (Table 3). Moreover, 3 isolates of $B$. bassiana (CN6T1W2, JN5R1W1 and JN5T2W1) showed 100\% mortality against both species of mosquito adults. Regarding lethality, all isolates were found to be slightly more pathogenic to Ae. albopictus than to Cx. pipiens adults. The $\mathrm{LT}_{50}$ values of $B$. bassiana CN6T1W2 and 
Table 3 Cumulative mortality \pm standard error (SE) and lethal time (days), with respective confidence interval (CI) to kill 50 or $90 \%\left(\mathrm{LT}_{50}\right.$ and $\left.\mathrm{LT}_{90}\right)$ Ae. albopictus and CX. pipiens adults treated with B. bassiana conidia $\left(10^{8}\right.$ conidia/mL)

\begin{tabular}{|c|c|c|c|c|c|}
\hline \multirow[t]{2}{*}{ Isolates } & \multicolumn{2}{|c|}{ Mortality \pm SE } & \multicolumn{2}{|c|}{ Lethal time $(\mathrm{Cl})$} & \multirow[t]{2}{*}{ Slope \pm SE } \\
\hline & 5 days & 10 days & $\mathrm{LT}_{50}$ & $\mathrm{LT}_{90}$ & \\
\hline \multicolumn{6}{|l|}{ Ae. albopictus } \\
\hline CN6T1W2 & $58.3 \pm 6.8^{\mathrm{cd}}$ & $100^{b}$ & $4.8(4.6-4.9)^{\mathrm{a}}$ & $5.8(5.5-6.2)^{\mathrm{a}}$ & $14.76 \pm 0.82$ \\
\hline JN5R1W1 & $72.3 \pm 10.1^{d}$ & $100^{b}$ & $4.5(4.2-4.8)^{\mathrm{a}}$ & $5.5(5.2-6.2)^{\mathrm{a}}$ & $14.41 \pm 0.78$ \\
\hline JN15T2W1 & $43.1 \pm 7.7^{\mathrm{bc}}$ & $100^{b}$ & $5.4(5.1-5.8)^{a}$ & $7.5(7-8.2)^{\mathrm{ab}}$ & $9.19 \pm 0.32$ \\
\hline KN16G1W1 & $21.6 \pm 2.8^{\mathrm{ab}}$ & $100^{b}$ & $5.5(3.6-7.7)^{\mathrm{a}}$ & $8.5(6.5-27.8)^{a b}$ & $6.91 \pm 0.26$ \\
\hline KB6S1W1 & - & $91.7 \pm 8.3^{b}$ & $8.2(7.7-8.8)^{b}$ & $11.3(10.2-13.6)^{b}$ & $9.32 \pm 0.43$ \\
\hline CN10G3W2 & $13.3 \pm 5.4^{\mathrm{a}}$ & $68.3 \pm 1.4^{\mathrm{a}}$ & $9.2(8.3-10.7)^{b}$ & $18.4(14.7-27)^{c}$ & $4.29 \pm 0.26$ \\
\hline$F_{5,8}$ & 15.87 & 6.28 & - & - & - \\
\hline$P$ & 0.001 & 0.012 & - & - & - \\
\hline \multicolumn{6}{|l|}{ Cx.pipiens } \\
\hline CN6T1W2 & $76.5 \pm 13.1^{b}$ & 100 & $4.3(3.8-4.7)^{\mathrm{a}}$ & $7.0(6.3-8.2)^{\mathrm{a}}$ & $6.03 \pm 0.2$ \\
\hline JN5R1W1 & $66.2 \pm 4.5^{b}$ & 100 & $4.4(3.7-5)^{\mathrm{a}}$ & $6.2(5.5-8.1)^{\mathrm{a}}$ & $8.33 \pm 0.28$ \\
\hline JN15T2W1 & $34.9 \pm 4.2^{\mathrm{ab}}$ & 100 & $5.2(4.8-5.5)^{\mathrm{ab}}$ & $7.0(6.5-7.7)^{\mathrm{a}}$ & $9.92 \pm 0.34$ \\
\hline KN16G1W1 & $52.9 \pm 12.5^{\mathrm{ab}}$ & $90.5 \pm 9.5$ & $5.5(4.8-6.1)^{\mathrm{ab}}$ & $8.1(7.2-9.9)^{\mathrm{a}}$ & $7.54 \pm 0.25$ \\
\hline KB6S1W1 & $39.7 \pm 15.3^{a b}$ & 100 & $5.2(4.6-5.6)^{\mathrm{ab}}$ & $7.9(7-9.3)^{\mathrm{a}}$ & $6.93 \pm 0.23$ \\
\hline CN10G3W2 & $13.6 \pm 3.7^{\mathrm{a}}$ & 100 & $6.3(4.9-7.9)^{b}$ & $10.1(8-20.4)^{b}$ & $6.15 \pm 0.25$ \\
\hline$F_{5,11}$ & 3.95 & 0.91 & - & - & - \\
\hline$P$ & 0.027 & 0.511 & - & - & - \\
\hline
\end{tabular}

Values, based on three repetitions, in the same column for each isolate followed by different letters were significantly different based on ANOVA and SNK test (cumulated mortalities; a-d) or their $\mathrm{Cl}(\mathrm{LT} ; \mathrm{a}-\mathrm{C})$. Cumulative control mortality was $\leq 5 \%$ at 10 -days after treatment

JN5R1W1 in Cx. pipiens were 4.3 and 4.4 days, respectively, which were lower than the values for the other 4 isolates, which were all more than 5.2 days. B. bassiana CN6T1W2 and JN5R1W1 also showed the lowest $\mathrm{LT}_{50}$ values for Ae. albopictus at 4.8 and 4.5 days, respectively. The $\mathrm{LT}_{90}$ values of $B$. bassiana CN6T1W2 and JN5R1W1 were also significantly lower than those of the other isolates. Thus, B. bassiana CN6T1W2 and JN5R1W1 were found to be the most virulent for both species of mosquitoes at the same time.

\section{Conidia productivity on millet grain}

The conidia productivity of the 6 isolates of $B$. bassiana that were simultaneously pathogenic to the two species of mosquitoes was evaluated on millet grain medium. All the isolates showed conidia productivity of 1.6$2.3 \times 10^{9}$ conidia/g at 7 days after inoculation; there was no significant difference in productivity (Fig. 1). At 14 days after inoculation, 5 isolates, excluding $B$. bassiana JN5R1W1, produced 2.1-2.5 $\times 10^{9}$ conidia/g, which was not significantly higher than that at 7 days. However, B. bassiana JN5R1W1 produced $3.8 \times 10^{9}$ conidia/g at 14 days after inoculation, showing a very high increase in productivity compared with other isolates.

\section{Discussion}

Finally, $B$. bassiana JN5R1W1 was selected as the most effective fungus for the simultaneous control of $A e$. albopictus and $C x$. pipiens adults and deposited in Korean Agricultural Culture Collection of National Institute of Agricultural Sciences with registration number of KACC83026BP. This fungal isolate showed high virulence against both species of mosquitoes and high conidia persistence and productivity. $\mathrm{LT}_{50}$ values by $B$. bassiana JN5R1W1 were 4.5 days (Ae. albopictus) and 4.4 days $(C x$. pipiens). Although there are few report of entomopathogenic fungal virulence on Ae. albopictus and Cx. pipiens adults, similar report has shown that $M$. anisopliae showed 3.1-4.1 days against Ae. aegypti adult (Scholte et al. 2007). To the best of our knowledge, this is the first report about $B$. bassiana isolate that has dual virulence to Ae. albopictus and Cx. pipiens adults. The need for the simultaneous control of Ae. albopictus and Cx. pipiens is very high because they transfer different diseases, but their distribution areas overlap greatly (Khaiboullina et al. 2018; Kraemer et al. 2015; Lounibos 2002). Until now, the control methods for these mosquitoes have been largely dependent on chemical insecticides. However, the development of other control methods is urgent because of the various side effects of chemical insecticides (Ariee et al. 2001; Damalas and Eleftherohorinos 2011; Mužinić 


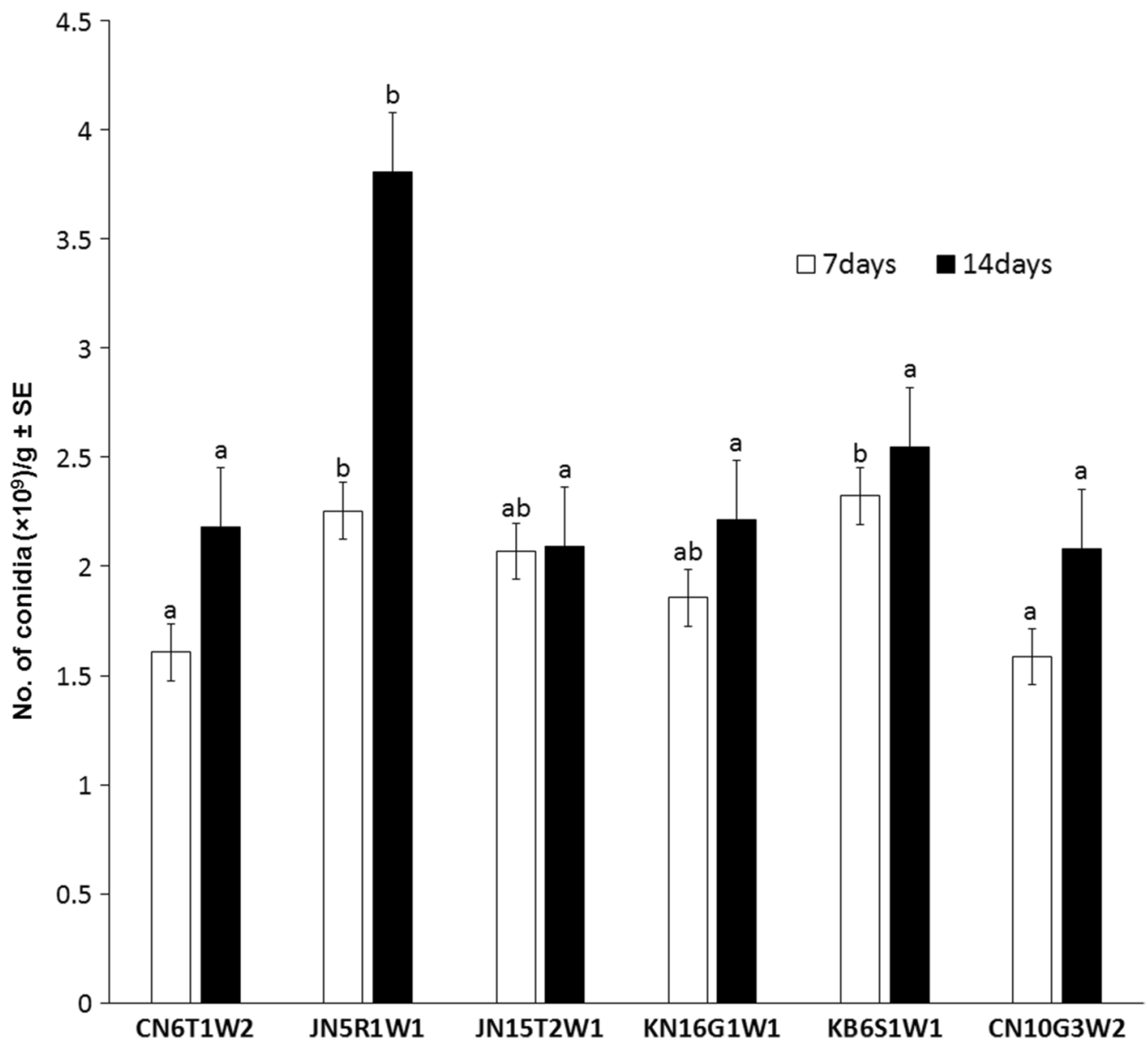

Fig. 1 Productivity of B. bassiana conidia on millet grain medium. Conidia were sampled at 7 days and 14 days after inoculation of each B. bassiana isolate. Data are expressed as the mean \pm standard error (SE). Values with different letters are significantly different $(p<0.05$, SNK test in one-way ANOVA). All experiments were replicated three times

and Želježić 2018). Therefore, the research and development of various control methods with relatively low environmental impacts, such as entomopathogenic fungi, has attracted much attention. However, studies on fungi pathogenic to Ae. albopictus and Cx. pipiens are scarcer than studies on other mosquito species. Much of the fungi research has been conducted for the control of $A e$. aegypti or Anopheles spp., and there have been many reports on various fungi, including $B$. bassiana and $M$. anisopliae, for these mosquito species (Huang et al. 2017; Scholte et al. 2004). There have been some reports of $M$. anisopliae for the larval and adult control of Ae. albopictus and B. bassiana for adult control using a contamination device, with remarkable results (Buckner et al. 2017; Snetselaar et al. 2014). In the case of $C x$. pipiens, the research is relatively limited and only fungal metabolites were considered for larval control (Weiser et al. 1992). Eco-friendly insecticides are mainly used for the control of mosquito larvae, and effective products such as Bti and
L. sphaericus have been developed and widely used. However, since the recently developed contamination device has been successful in the control of adult mosquitoes (Buckner et al. 2017; Snetselaar et al. 2014), the selection of a fungus to control mosquito adults is considered to be important. Although mosquito control using fungi has been considered, the fact that only one contamination device has been produced may be due to the ineffective methods of spraying fungal conidia for mosquito adults and treating water containing mosquito larvae. Therefore, it is considered that a treatment method similar to that of the contamination device is the most efficient at present; thus, the proper selection of a fungus to be utilized with this treatment method is becoming important. The fungal isolate selected in this study is expected to be effective for the simultaneous control of Ae. albopictus and $C x$. pipiens adults.

In addition, the results of our study showed that 12 isolates and 23 isolates of B. bassiana were pathogenic 
to $C x$. pipiens and Ae. albopictus, respectively, and Ae. albopictus was more susceptible to $B$. bassiana. However, until now, the pathogenicity of some $M$. anisopliae (Scholte et al. 2007) and B. bassiana strains (Buckner et al. 2017) has been tested on Ae. albopictus adults, but the pathogenicity of $M$. anisopliae and B. bassiana has not been reported for $C x$. pipiens adults. Therefore, further research on the susceptibility of these mosquito species to $B$. bassiana using more isolates is needed. In particular, only 6 isolates of $B$. bassiana were found to be simultaneously pathogenic to these two species of mosquitoes; reports of a fungus that is simultaneously pathogenic to two or more species of mosquitoes are rare. Similar studies have reported simultaneous pathogenicity in Ae. aegypti and Ae. Albopictus, which are of the same genus (Buckner et al. 2017; Scholte et al. 2007). However, there have been no reports on the selection of fungi that are simultaneously pathogenic to two species of mosquitoes from different genera.

In our study, we attempted to increase the industrial usefulness of selected fungi by using only fungal isolates that are expected to be highly persistent in the natural environment. Traditionally, the selection of entomopathogenic fungi for the development of insecticides has focused mainly on their virulence to target insects. However, in terms of industrial usefulness, the persistence of fungicidal agents when applied in outdoor environments or during the distribution process is just as important as virulence (Fernandes et al. 2015; Lee et al. 2015). Therefore, in recent years, there have been an increasing number of attempts to evaluate various factors simultaneously and to select suitable fungi for control. Many environmental factors affect the persistence of fungi, but the most significant effects are thought to be thermotolerance and UV-B tolerance (Fernandes et al. 2008, 2015; Lee et al. 2015).

Thermotolerance is closely related to the production of reactive oxygen species (ROS) (Zhang et al. 2017) and heat shock proteins (HSPs) (Xie et al. 2010). Thermotolerance could be enhanced by the overexpression of HSP25 and pyruvate kinase or superoxide dismutase (Wu et al. 2019; Xie et al. 2010). In addition, it is possible to increase the thermotolerance of fungus by controlling the nutrients or the osmotic pressure of the medium (Rangel et al. 2015). Such medium conditioning could also enhance UV tolerance. UV tolerance is related to the conidial colour of fungus; darkly pigmented conidia are more tolerant to UV radiation than less-pigmented conidia (Rangel et al. 2006). However, it was also reported that conidial pigmentation may be important to protect from UV radiation, but it is not crucial (Fernandes et al. 2015). In our results, although $B$. bassiana with white conidia was used, most of the isolates showed high UV-B tolerance with more than 50\%. UV-tolerance can be assessed with various UV doses, but we set the standard of $0.2 \mathrm{~J} / \mathrm{cm}^{2}$ for various tolerances of fungi according to the previous report (Fernandes et al. 2015). These various manipulations and controls may enhance the tolerance of fungus, but they may have limitations if the selected fungus does not have high thermotolerance. Therefore, it is important to select and use a fungus with high thermotolerance. In the present study, only $B$. bassiana isolates with high thermotolerance and UV-B tolerance were used, so the practical use of the finally selected isolate is be expected to be high.

To develop appropriate fungal insecticides, virulence to the target insect, conidia persistence and conidia productivity are important factors (Lopez-Perez et al. 2015; Muñiz-Paredes et al. 2017). Recently, several studies have been conducted on various media that can increase the conidial productivity of fungi (Lopez-Perez et al. 2015; Kim et al. 2014; Safavi et al. 2007; Shah et al. 2005). However, when the basic conidia productivity of the fungus is low, the replacement of the medium is a limitation. Therefore, a comparative evaluation of the conidia productivity of fungi is also important for proper fungus selection. The productivity of conidia as an evaluation factor for the selection of the final fungal isolates was added as a selection index in our study. Conidia productivity was evaluated on millet grain medium, which was reported to be effective for the production and tolerance of conidia (Kim et al. 2011). The conidia productivity of $B$. bassiana in various solid media was reported with approximately $1.0-2.9 \times 10^{10}$ conidia/g on dry substrate, but it was approximately $1.8-2.2 \times 10^{9}$ conidia/g on wet substrate as our same condition (Lopez-Perez et al. 2015). Additionally, the conidia productivity in the Italian millet medium used in our study was reported to be approximately $1.5-2.5 \times 10^{9}$ conidia/g (Song et al. 2019). This indicated that our finally selected $B$. bassiana JN5R1W1 has the high conidia productivity with $3.8 \times 10^{9}$ conidia/g. The difference in conidia productivity between the fungal isolates in our study indicated that this comparison was necessary to select the optimal fungal isolate. Although our study used only millet grain and evaluated only conidia productivity, it may be beneficial to perform further studies on the virulence and tolerance of fungal conidia produced on various media.

In conclusion, $B$. bassiana JN5R1W1 was finally selected for the simultaneous control Ae. albopictus and $C x$. pipiens adults through evaluations of virulence, persistence and productivity of the fungal conidia. The development of successful fungal insecticides containing this fungal isolate for the simultaneous control of two species of mosquitoes is expected in further studies on optimal formulations and field tests. 


\section{Supplementary information}

Supplementary information accompanies this paper at https://doi. org/10.1186/s13568-019-0933-z.

Additional file 1: Table S1. Thermotolerance and UV-B tolerance of Beauveria bassiana isolates from Korea.

Additional file 2: Figure S1. Cadavers of Ae. albopictus (A) and Cx. pipiens (B) adults showing sporulation of B. bassiana.

\section{Abbreviations}

UV: ultraviolet; RH: relative humidity; PDA: potato dextrose agar; SDA: Sabouraud dextrose agar; SDA-B: Sabouraud dextrose agar with benomyl; $\mathrm{LT}_{50}$ : the median lethal time; $\mathrm{LT}_{90}$ : the $90 \%$ lethal time.

\section{Acknowledgements}

Not applicable.

\section{Authors' contributions}

JYL and RMW designed the study and performed most experiments. CJC maintained mosquitoes and evaluated the pathogenicity. TYS evaluated the thermotolerance and UV-B tolerance of fungal conidia and discussed the results. WSG and SDW conceived and designed the study, and drafted the manuscript. All authors read and approved the final manuscript.

\section{Funding}

This research was supported by Government-wide R\&D Fund project for infectious disease research (GFID), Republic of Korea (Grant Number: HG18C0050).

\section{Availability of data and materials}

All data generated during this study are included in this article and its additional files.

\section{Ethics approval and consent to participate}

Our experimental animals are Aedes albopictus and Culex pipiens, which do not involve animal ethical issues.

\section{Consent for publication}

Not applicable.

\section{Competing interests}

The authors declare that they have no competing interests.

\section{Author details}

${ }^{1}$ Department of Agricultural Biology, College of Agriculture, Life \& Environment Science, Chungbuk National University, Cheongju 28644, Republic of Korea. ${ }^{2}$ Department of Agricultural Biotechnology, College of Agriculture \& Life Science, Seoul National University, Seoul 08826, Republic of Korea.

${ }^{3}$ Department of Agricultural Biology, College of Agriculture \& Life Sciences, Chonbuk National University, Jeonju 54896, Republic of Korea.

Received: 4 August 2019 Accepted: 13 December 2019

Published online: 21 December 2019

\section{References}

Ariee F, Ernst WH, Sijm DT (2001) Natural and synthetic organic compounds in the environment- a symposium report. Environ Toxicol Pharmacol 10:65-80

Berry C (2011) The bacterium, Lysinibacillus sphaericus, as an insect pathogen. J Invertebr Pathol 109:1-10. https://doi.org/10.1016/j.jip.2011.11.008

Buckner EA, Williams KF, Marsicano AL, Latham MD, Lesser CR (2017) Evaluating the vector control potential of the $\ln 2 C_{a r}{ }^{\circledR}$ mosquito trap against Aedes aegypti and Aedes albopictus under semifield conditions in Manatee county, Florida. J Am Mosq Control Assoc 33:193-199. https://doi. org/10.2987/17-6642R.1
Damalas CA, Eleftherohorinos IG (2011) Pesticide exposure, safety issues, and risk assessment indicators. Int J Environ Res Public Health 8:1402-1419. https://doi.org/10.3390/ijerph8051402

Farajollahi A, Fonseca DM, Kramer LD, Kilpatrick AM (2011) "Bird biting" mosquitoes and human disease: a review of the role of Culex pipiens complex mosquitoes in epidemiology. Infect Genet Evol 11:1577-1585. https://doi. org/10.1016/j.meegid.2011.08.013

Fernandes ÉK, Rangel DE, Moraes AM, Bittencourt VR, Roberts DW (2008) Cold activity of Beauveria and Metarhizium, and thermotolerance of Beauveria. J Invertebr Pathol 98:69-78. https://doi.org/10.1016/j.jip.2007.10.011

Fernandes ÉK, Rangel DE, Braga GU, Roberts DW (2015) Tolerance of entomopathogenic fungi to ultraviolet radiation: a review on screening of strains and their formulation. Curr Genet 61:427-440. https://doi. org/10.1007/s00294-015-0492-z

Fernandes JN, Moise IK, Maranto GL, Beier JC (2018) Revamping mosquitoborne disease control to tackle future threats. Trends Parasitol 34:359_ 368. https://doi.org/10.1016/j.pt.2018.01.005

Harrington LC, Edman JD, Scott TW (2001) Why do female Aedes aegypti (Diptera: Culicidae) feed preferentially and frequently on human blood? J Med Entomol 38:411-422. https://doi.org/10.1603/0022-2585-38.3.411

Hemingway J, Ranson H (2000) Insecticide resistance in insect vectors of human disease. Annu Rev Entomol 45:371-391. https://doi.org/10.1146/ annurev.ento.45.1.371

Hochedez P, Jaureguiberry S, Debruyne M, Bossi P, Hausfater P, Brucker G, Bricaire $F$, Caumes $E$ (2006) Chikungunya infection in travelers. Emerg Infect Dis 12:1565-1567. https://doi.org/10.3201/eid1210.060495

Huang YS, Higgs S, Vanlandingham DL (2017) Biological control strategies for mosquito vectors of Arboviruses. Insects 8:E21. https://doi.org/10.3390/ insects 8010021

Khaiboullina S, Uppal T, Martynova E, Rizvanov A, Baranwal M, Verma SC (2018) History of ZIKV infections in India and management of disease outbreaks. Front Microbiol 9:2126. https://doi.org/10.3389/fmicb.2018.02126

Kim JS, Kassa A, Skinner M, Hata T, Parker BL (2011) Production of thermotolerant entomopathogenic fungal conidia on millet grain. J Ind Microbiol Biotechnol 38:697-704. https://doi.org/10.1007/s10295-010-0850-2

Kim JJ, Xie L, Han JH, Lee SY (2014) Influence of additives on the yield and pathogenicity of conidia produced by solid state cultivation of an Isaria javanica isolate. Mycobiology 42:346-352. https://doi.org/10.5941/ MYCO.2014.42.4.346

Kraemer MU, Sinka ME, Duda KA, Mylne AQ, Shearer FM, Barker CM, Moore CG, Carvalho RG, Coelho GE, Van Bortel W, Hendrickx G, Schaffner F, Elyazar IR, Teng HJ, Brady OJ, Messina JP, Pigott DM, Scott TW, Smith DL, Wint GR, Golding N, Hay SI (2015) The global distribution of the arbovirus vectors Aedes aegypti and Ae. albopictus. eLife 4:e08347. https://doi.org/10.7554/ eLife.08347

Lacey LA, Frutos R, Kaya HK, Vail P (2001) Insect pathogens as biological control agents: do they have a future? Biol Control 21:230-248. https://doi. org/10.1006/bcon.2001.0938

Lacey LA, Grzywacz D, Shapiro-Ilan DI, Frutos R, Brownbridge M, Goettel MS (2015) Insect pathogens as biological control agents: back to the future. J Invertebr Pathol 132:1-41. https://doi.org/10.1016/j.jip.2015.07.009

Lee WW, Shin TY, Bae SM, Woo SD (2015) Screening and evaluation of entomopathogenic fungi against the green peach aphid, Myzus persicae, using multiple tools. J Asia Pac Entomol 18:607-615. https://doi. org/10.1016/j.aspen.2015.07.012

Liu N (2015) Insecticide resistance in mosquitoes: impact, mechanisms, and research directions. Annu Rev Entomol 60:537-559. https://doi. org/10.1146/annurev-ento-010814-020828

Lopez-Perez M, Rodriguez-Gomez D, Loera O (2015) Production of conidia of Beauveria bassiana in solid-state culture: current status and future perspectives. Crit Rev Biotechnol 35:334-341. https://doi.org/10.3109/07388 551.2013 .857293

Lounibos LP (2002) Invasions by insect vectors of human disease. Annu Rev Entomol 47:233-266. https://doi.org/10.1146/annurev.ento.47.09120 1.145206

Mayer SV, Tesh RB, Vasilakis N (2017) The emergence of arthropod-borne viral diseases: a global prospective on dengue, chikungunya and Zika fevers. Acta Trop 166:155-163. https://doi.org/10.1016/j.actatropica.2016.11.020

Moyes CL, Vontas J, Martins AJ, Ng LC, Koou SY, Dusfour I, Raghavendra K, Pinto J, Corbel V, David JP, Weetman D (2017) Contemporary status of insecticide resistance in the major Aedes vectors of arboviruses infecting 
humans. PLoS Neglect Trop Dis 11:e0005625. https://doi.org/10.1371/ journal.pntd.0005625

Muñiz-Paredes F, Miranda-Hernández F, Loera O (2017) Production of conidia by entomopathogenic fungi: from inoculants to final quality tests. World J Microbiol Biotechnol 33:57. https://doi.org/10.1007/s11274-017-2229-2

Mužinić V, Želježić D (2018) Non-target toxicity of novel insecticides. Arh Hig Rada Toksikol 69:86-102. https://doi.org/10.2478/aiht-2018-69-3111

Patterson GM (2016) Looking backward, looking forward: the long, torturous struggle with mosquitoes. Insects 7:E56. https://doi.org/10.3390/insec ts7040056

Rangel DEN, Butler MJ, Torabinejad J, Anderson AJ, Braga GUL, Day AW, Roberts DW (2006) Mutants and isolates of Metarhizium anisopliae are diverse in their relationships between conidial pigmentation and stress tolerance. J Invertebr Pathol 93:170-182. https://doi.org/10.1016/j. jip.2006.06.008

Rangel DE, Braga GU, Fernandes EK, Keyser CA, Hallsworth JE, Roberts DW (2015) Stress tolerance and virulence of insect-pathogenic fungi are determined by environmental conditions during conidial formation. Curr Genet 61:383-404. https://doi.org/10.1007/s00294-015-0477-y

Safavi SA, Shah FA, Pakdel AK, Reza Rasoulian G, Bandani AR, Butt TM (2007) Effect of nutrition on growth and virulence of the entomopathogenic fungus Beauveria bassiana. FEMS Microbiol Lett 270:116-123. https://doi. org/10.1111/j.1574-6968.2007.00666.x

Samish M, Rot A, Ment D, Barel S, Glazer I, Gindin G (2014) Efficacy of the entomopathogenic fungus Metarhizium brunneum in controlling the tick Rhipicephalus annulatus under field conditions. Vet Parasitol 206:258-266. https://doi.org/10.1016/j.vetpar.2014.10.019

Scholte EJ, Knols BG, Samson RA, Takken W (2004) Entomopathogenic fungi for mosquito control: a review. J Insect Sci 4:19. https://doi.org/10.1093/ jis/4.1.19

Scholte EJ, Takken W, Knols BG (2007) Infection of adult Aedes aegypti and Ae. albopictus mosquitoes with the entomopathogenic fungus Metarhizium anisopliae. Acta Trop 102:151-158. https://doi.org/10.1016/j.actatropic a.2007.04.011

Shah FA, Wang CS, Butt TM (2005) Nutrition influences growth and virulence of the insect-pathogenic fungus Metarhizium anisopliae. FEMS Microbiol Lett 251:259-266. https://doi.org/10.1016/j.femsle.2005.08.010

Shin TY, Lee WW, Ko SH, Ji Z, Shin DH, Son KH, Park HY, Woo SD (2011) Preliminary evaluation of Paecilomyces lilacinus HY-4 to control Tetranychus urticae. Int J Indust Entomol 22:25-28. https://doi.org/10.7852/ ijie.2011.22.1.25
Shin TY, Lee WW, Ko SH, Choi JB, Bae SM, Choi JY, Lee KS, Je YH, Jin BR, Woo SD (2013) Distribution and characterisation of entomopathogenic fungi from Korean soils. Biocontrol Sci Techn 23:288-304. https://doi. org/10.1080/09583157.2012.756853

Shuman EK (2011) Global climate change and infectious diseases. Int J Occup Environ Med 2:11-19

Snetselaar J, Andriessen R, Suer RA, Osinga AJ, Knols BG, Farenhorst M (2014) Development and evaluation of a novel contamination device that targets multiple life-stages of Aedes aegypti. Parasit Vectors 7:200. https:// doi.org/10.1186/1756-3305-7-200

Song MH, Yu JS, Kim S, Lee SJ, Kim JC, Nai YS, Shin TY, Kim JS (2019) Downstream processing of Beauveria bassiana and Metarhizium anisopliaebased fungal biopesticides against Riptortus pedestris: solid culture and delivery of conidia. Biocontrol Sci Techn 29:514-532. https://doi. org/10.1080/09583157.2019.1566951

Weaver S, Scott C, Charlier C, Vasilakis N, Lecuit M (2018) Zika, chikungunya, and other emerging vectorborne viral diseases. Annu Rev Med 69:395408. https://doi.org/10.1146/annurev-med-050715-105122

Weiser J, Matha V, Zizka Z, Jegorov A (1992) Ultrastructural changes in Culex pipiens larvae treated with tolypin, the insecticidal metabolite of Tolypocladium inflatum gams (Deuteromycetes). Cytobios 69:179-186

Wong PS, Li MZ, Chong CS, Ng LC, Tan CH (2013) Aedes (Stegomyia) albopictus (Skuse): a potential vector of Zika virus in Singapore. PLoS Negl Trop Dis 7:e2348. https://doi.org/10.1371/journal.pntd.0002348

Wu C, Zhang X, Fang W (2019) Increasing pyruvate concentration enhances conidial thermotolerance in the entomopathogenic fungus Metarhizium robertsii. Front Microbiol. 10:519. https://doi.org/10.3389/fmicb .2019 .00519

Xie XQ, Wang J, Huang BF, Ying SH, Feng MG (2010) A new manganese superoxide dismutase identified from Beauveria bassiana enhances virulence and stress tolerance when overexpressed in the fungal pathogen. Appl Microbiol Biotech 86:1543-1553. https://doi.org/10.1007/s0025 3-010-2437-2

Zhang X, St. Leger RJ, Fang W (2017) Pyruvate accumulation is the first line of cell defense against heat stress in a fungus. MBio 8:e01284-17. https://doi. org/10.1094/PDIS-04-17-0573-RE

\section{Publisher's Note}

Springer Nature remains neutral with regard to jurisdictional claims in published maps and institutional affiliations.

\section{Submit your manuscript to a SpringerOpen ${ }^{\odot}$ journal and benefit from:}

- Convenient online submission

- Rigorous peer review

- Open access: articles freely available online

- High visibility within the field

- Retaining the copyright to your article

Submit your next manuscript at $\boldsymbol{\nabla}$ springeropen.com 